\title{
CONTROLE ESTATÍSTICO APLICADO DA COLHEITA MECANIZADA DE CAFEEIROS IRRIGADOS
}

\author{
Anselmo Augusto de Paiva Custódio ${ }^{1}$; Rouverson Pereira da Silva ${ }^{2}$; Leandro Borges Lemos ${ }^{1}$; \\ Anderson de Toledo ${ }^{2}$; Leomar Paulo de Melo²; Adriano Augusto de Paiva Custódio ${ }^{3}$

\footnotetext{
${ }^{1}$ Departamento de Produção Vegetal, UNESP, Jaboticabal-SP. E-mail: b1uflagro@ yahoo.com.br

${ }^{2}$ Departamento de Engenharia Rural, UNESP, Jaboticabal-SP.

${ }^{3}$ Departamento de Engenharia, UFLA, Lavras-MG.
}

\section{RESUMO}

A utilização de colhedoras requer regulagens adequadas e o controle da qualidade do processo de colheita do café é fundamental para a redução das perdas e danos na lavoura. Diante disso, este trabalho teve como objetivo avaliar a operação de colheita mecanizada do café irrigado sob a óptica do controle estatístico de processo, utilizando cartas de controle, em duas velocidades operacionais. O estudo foi conduzido em área da empresa Cambuhy Agrícola Ltda, município de Matão, SP, durante a colheita na safra 2008/2009. Foram avaliados volume de café caído no chão (perdas), porcentual de danos (desfolha) e eficiência da colheita. Não foram observadas influências das velocidades nas variáveis avaliadas e o processo foi considerado sob controle para as variáveis danos e perdas. As perdas e danos foram menores na face de exposição leste. A utilização de cartas de controle contribuiu para a melhoria na operação da colheita mecanizada do café irrigado.

Palavras-chave: Coffea arabica, cartas de controle, desempenho operacional

\section{STATISTICAL CONTROL APPLIED TO MECHANIZED HARVESTING OF IRRIGATED COFFEE TREES}

\section{ABSTRACT}

The use of harvesters requires appropriate adjustments and the quality control of coffee harvesting process is essential to reduce losses and damage. Therefore, this work aimed at evaluate the operation of mechanical harvesting of irrigated coffee from the perspective of statistical process control, using control charts in two operating speeds. The study was conducted in the area of company Cambuhy Agricola Ltda, in Matão, SP, Brazil during the 2008/2009 harvest. We evaluated the volume of coffee fell on the soil (losses), percentage of damage (defoliation) and harvest efficiency. There were no influences of the velocities in the variables studied and the process was considered under control for variables damages and losses. The damages were lower at the faces of the East side. The use of control charts was useful to evaluating the quality of the irrigated coffee harvest.

Key words: Coffea arabica, control charts, operational performance

\section{INTRODUÇÃO}

A colheita do café, perante os demais procedimentos para a produção dessa commodity agrícola, é uma atividade cara por representar $30 \%$ do custo de produção e onerosa por utilizar $50 \%$ do contingente de mão-de-obra (MATIELLO et al., 2009). O preço do café pode ser alterado de forma significativa por parâmetros de qualidade, 
mas frequentemente a colheita seletiva dos frutos é associada à boa qualidade do produto, procedimento este que pode ser realizado por meio de vibrações mecânicas (SANTOS et al., 2010).

$\mathrm{Na}$ colheita de café verde, pelo fato dos frutos possuírem teor de água entre $50 \mathrm{e}$ $70 \%$ apresenta prejuízos à bebida e também maior desgaste às plantas, pois os frutos verdes necessitam de maior esforço de desprendimento em relação aos maduros (REZENDE et al. 2006). De acordo com Silva et al. (2008a), é necessário ajustar a vibração das varetas da colhedora para que se possa realizar a colheita seletiva, retirando-se o maior número de frutos maduros e deixando a maioria dos verdes na planta. Porém, deve-se considerar que a força necessária para o desprendimento dos frutos difere em cada estádio de maturação (SILVA et al., 2010).

Quanto a produtividade do cafeeiro, Oliveira (2008) cita a necessidade de se conduzir ensaios em diferentes regiões a fim de se obter a forma correta de orientação para o plantio das linhas dos cafeeiros que proporcionem a melhor distribuição da irradiação interceptada nos dois lados da linha de cultivo, pois se tem observado considerável variação da produtividade nas diferentes faces. Além disso, Santinato et al. (2008) relatam que além de outros fatores, também a face de exposição das plantas influencia na maturação dos frutos, interferindo na definição da época para se iniciar a colheita.

Outra questão relevante é a velocidade de deslocamento da colhedora, uma vez que este parâmetro está diretamente relacionado ao desempenho operacional e à ocorrência de danos e perdas durante a colheita (OLIVEIRA et al., 2007). Uma maneira de se detectar rapidamente alterações dos parâmetros de determinados processos, como a colheita mecanizada de café, para que os problemas possam ser corrigidos, é por meio do uso do controle estatístico de qualidade, que tem apresentado bons resultados na agropecuária, em especial no uso em operações mecanizadas (SILVA et al., 2008b). Cartas de controle têm sido amplamente utilizadas no controle de qualidade, pois para se realizar qualquer tipo de análise estatística, é fundamental que o processo esteja sob controle e mantenha uma estabilidade ao longo do tempo (MINITAB, 2003).

Este trabalho teve por objetivo avaliar, por meio do controle estatístico de processo, os efeitos de duas velocidades nas faces de exposição leste e oeste na orientação de plantio da lavoura quanto as perdas e danos provocados às plantas de café e na eficiência de derriça.

\section{MATERIAL E MÉTODOS}

O experimento foi conduzido durante a colheita da safra 2008/2009 em área comercial da Empresa Cambuhy Agrícola Ltda., localizada na rodovia Washington Luiz, Km 307, município de Matão, SP. O cafeeiro foi implantado em janeiro 2006, localizado nas coordenadas geodésicas de latitude $21^{\circ} 38^{\prime} 58,56^{\prime}$ ' Sul e longitude $48^{\circ} 31^{\prime}$ $05,10^{\prime}$ ' Oeste, com altitude entre 590 a 615 metros e declividade média de 5\%. Foram avaliadas plantas de café da cultivar Catuaí Amarelo IAC 62, no espaçamento $3,50 \mathrm{~m}$ entre linhas e $0,50 \mathrm{~m}$ entre plantas, com densidade populacional de 5.714 plantas ha 1, em solo classificado como Argissolo Vermelho Amarelo eutrófico (EMBRAPA, 2006). O clima da região, segundo classificação climática de Köppen, é do tipo Aw, caracterizado por ser subtropical mesotérmico, úmido, com chuvas de verão, e estiagem branda no inverno. Os cafeeiros se encontravam sob sistema de irrigação localizada, tipo gotejo, de acionamento elétrico com uma única linha de irrigação por linha de plantio.

A colheita dos cafeeiros foi realizada por uma colhedora automotriz Jacto, modelo 
K-3 Millennium, fabricada em 2008, com 287 horas de trabalho no início do experimento. Esta máquina opera a cavaleiro nas linhas das plantas, com as hastes vibratórias atuando em torno de cada planta, desprendendo os grãos, sendo esses coletados por um conjunto de lâminas retráteis fechando o espaço sob a saia do cafeeiro. A altura aferida entre o solo e o conjunto de lâminas retráteis no momento da colheita foi de $0,40 \mathrm{~m}$. Foram colhidas duas linhas de plantio, próximas entre si, em uma única passada. No momento da colheita foram retiradas amostras de café derriçado nas parcelas experimentais apresentando porcentual médio de maturação dos frutos nos estádios verde, cereja, passa e seco de $43 \%, 18 \%, 27 \%$ e $12 \%$, respectivamente. A carga pendente média obtida foi de 4,76 1 planta $^{-1}$. A produção de cada face das plantas foi quantificada individualmente para posterior determinação da produtividade média (1 planta $\left.^{-1}\right)$.

A vibração das hastes foi mantida em $850 \mathrm{rpm}(16,67 \mathrm{~Hz})$, sendo utilizado um delineamento inteiramente casualizado em faixas, em esquema fatorial $2 \times 2$ com 10 repetições. Os fatores considerados foram duas velocidades médias de operação, sendo uma para cada linha de plantio $\left(\mathrm{V}_{1}: 0,34 \mathrm{~m} \mathrm{~s}^{-}\right.$ ${ }^{1}$ e $\mathrm{V}_{2}: 0,45 \mathrm{~m} \mathrm{~s}^{-1}$ ) e duas faces de exposição na orientação de plantio em cada linha de plantio (leste e oeste). As velocidades para a operação da colhedora foram determinadas a partir da velocidade média normal de operação utilizada pela fazenda $\mathrm{CY}$, observada no momento da colheita $\left(V_{1}\right)$, sendo a segunda velocidade $\left(\mathrm{V}_{2}\right)$ escolhida a partir dos resultados observados por Oliveira et al. (2007).

Cada parcela amostral foi constituída por 5 plantas, nas quais a colhedora operava sobre panos que recobriam o chão sob saia das árvores. Os pontos amostrados distanciavam entre si em $20 \mathrm{~m}$, sendo observados $80 \mathrm{~m}$ para marcação da primeira parcela amostrada, no intuito de se obter a estabilização do desempenho de derriça pela colhedora. Na determinação da perda do café caído no chão após a passagem da colhedora, apenas os frutos que caíram sobre o pano nesta área foram recolhidos após a passagem da colhedora. Em seguida foi calculada a média de perdas de café por planta, separados pela face. Para determinação do café remanescente na planta após a passagem da máquina, procedeu-se a derriça manual das cinco plantas avaliadas, e os frutos não colhidos foram quantificados para posterior cálculo da média em 1 planta ${ }^{-1}$.

A quantidade total de café colhido foi calculada pela diferença entre a carga total da planta e a quantidade de café perdido e de café pendente, conforme equação 1:

$C_{C}=C_{T P}-C_{P D}-C_{P T}$, em que:

$\mathrm{C}_{\mathrm{C}}$ : Café colhido (1 planta $\left.^{-1}\right)$;

$\mathrm{C}_{\mathrm{TP}}$ : Carga total de café (1 planta $\left.{ }^{-1}\right)$;

$\mathrm{C}_{\mathrm{PD}}$ : Perda de café (1 planta $\left.^{-1}\right)$;

$\mathrm{C}_{\mathrm{PT}}$ : Café pendente $\left(1\right.$ planta $\left.^{-1}\right)$.

A eficiência de derriça $\left(E_{D}\right)$, ou seja, o volume da carga inicial de café que foi derriçado pela colhedora em cada parcela, foi determinado por meio da equação 2 :

$$
E_{D}=\frac{C_{C}+C_{P D}}{C_{T P}} .100
$$

Os danos provocados pela ação das hastes vibratórias da colhedora no cafeeiro foram determinados pelo índice de desfolha, calculado a partir da massa de folhas e ramos arrancados, em relação ao volume de café colhido. A massa de folhas arrancadas foi determinada recolhendo-se e pesando-se todas as folhas, ramos e fragmentos de material vegetal encontrados sobre os panos, e calculando-se posteriormente a média por planta. 
Os resultados foram analisados estatisticamente por meio da análise de variância (teste $F$ ) e quando houve significância, aplicou-se o teste de Tukey a $5 \%$ de probabilidade para comparação entre as médias, com auxílio do programa computacional Minitab $^{\circledR} 15$ (MINITAB, 2007). Para avaliar a qualidade da operação de colheita, utilizou-se de cartas de controle para valores individuais e amplitudes entre pontos, geradas também pelo programa computacional Minitab $^{\circledR}$ 15. O programa computacional Minitab ${ }^{\circledR} 15$ avalia se o processo está sob controle, estando fora de controle quando algum ponto apresentar valor maior que três vezes o desvio-padrão da média, ou seja, estar fora dos limites de controle.

As cartas de controle apresentam como linha central a média geral e a amplitude média, respectivamente, e limites superior e inferior de controle, definidos como LSC e LIC, calculados com base no desvio-padrão das variáveis (para LSC, média mais três vezes o desvio-padrão, e para LIC, média menos três vezes o desvio, quando maior que zero).

\section{RESULTADOS E DISCUSSÃO}

Os danos causados pela colhedora e a eficiência da colheita apresentaram baixos coeficientes de variação, de $23,58 \%$ e $4,31 \%$, respectivamente. Nas perdas, o valor de coeficiente de variação foi alto, de $77,54 \%$, o que pode estar relacionado a possíveis erros de natureza não-controlada (Tabela 1).

A velocidade de deslocamento bem como a interação velocidade de deslocamento e face de exposição não influenciou as variáveis estudadas. Porém, observou-se que isoladamente o fator face de exposição das plantas na linha de plantio influenciou as variáveis perdas e danos às plantas, que foram maiores na face oeste. Isso possivelmente ocorreu devido na face das plantas voltadas para o leste apresentarem menor crescimento de ramos, com diminuição de área fotossintética (enfolhamento) em relação à face oeste, acarretando assim menores danos e, possivelmente, menores perdas durante a colheita.

Tabela 1. Síntese dos valores para o teste de médias e análise de variância das variáveis analisadas danos as plantas, perdas na derriça e eficiência de colheita dos cafeeiros Catuaí Amarelo IAC 62. UNESP, Jaboticabal, SP, $2012^{1}$.

\begin{tabular}{|c|c|c|c|}
\hline Fatores estudados & 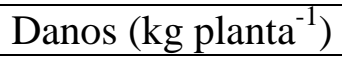 & Perdas (1 planta $\left.{ }^{-1}\right)$ & Eficiência $(\%)$ \\
\hline \multicolumn{4}{|l|}{ Velocidade (V) } \\
\hline $\mathrm{V}_{1}$ & $0,092 \mathrm{a}$ & $0,131 \mathrm{a}$ & $94,905 \mathrm{a}$ \\
\hline $\mathrm{V}_{2}$ & $0,093 \mathrm{a}$ & $0,157 \mathrm{a}$ & $93,445 \mathrm{a}$ \\
\hline \multicolumn{4}{|l|}{ Face de exposição (F) } \\
\hline leste & $0,081 \mathrm{a}$ & $0,068 \mathrm{a}$ & 94,716 a \\
\hline oeste & $0,104 \mathrm{~b}$ & $0,220 \mathrm{~b}$ & $93,634 \mathrm{a}$ \\
\hline \multicolumn{4}{|l|}{ Análise de Variância } \\
\hline $\mathrm{V}$ & $0,844^{\mathrm{ns}}$ & $0,326^{\mathrm{ns}}$ & $0,260^{\mathrm{ns}}$ \\
\hline $\mathrm{F}$ & $0,001^{* *}$ & $0,001^{* *}$ & $0,406^{\mathrm{ns}}$ \\
\hline $\mathrm{V}_{\mathrm{x}} \mathrm{F}$ & $0,922^{\mathrm{ns}}$ & $0,909^{\mathrm{ns}}$ & $0,659^{\mathrm{ns}}$ \\
\hline $\mathrm{CV}(\%)$ & 23,58 & 77,54 & 4,31 \\
\hline
\end{tabular}


De acordo com Matiello et al. (2004), em região de temperatura média elevada, o efeito da face de exposição da linha de cafeeiros, ocasiona escaldadura nas folhas e superbrotamento de ramos terciários, de modo que a face dos cafeeiros voltada para o sol da tarde sempre permanece mais amarelada. Por outro lado, Alves et al. (2004) avaliando a influência da exposição de cafeeiros sobre a produtividade e qualidade do café, encontraram efeito positivo da face oeste sobre a produtividade e a qualidade do café, porém em região de menor temperatura média. Oliveira (2008) cita que em regiões predominantemente quentes o lado do cafeeiro que recebe maior insolação produz menos, já em regiões frias, a produção é menor no lado do cafeeiro que recebe menos insolação e essa variação na produção em faces opostas numa linha de plantio pode ser atribuída aos diferentes níveis de energia radiante interceptada por essas faces na planta.

No presente trabalho, cuja colheita foi realizada com uma única passada da colhedora, foram observados valores reduzidos para os danos às plantas, com valores de $81,00 \mathrm{~g} \mathrm{planta}^{-1}$ (face leste) a 104,00 $\mathrm{g} \mathrm{planta}^{-1}$ (face oeste). Este valores encontram-se abaixo dos 700,00 $\mathrm{g} \mathrm{planta}^{-1}$ encontrados por Oliveira et al. (2007) para colheita realizada com vibração de $765 \mathrm{rpm}$ $(15 \mathrm{~Hz})$ e velocidade de $0,45 \mathrm{~m} \mathrm{~s}^{-1}$, valores menores que os encontrados no presente trabalho, em que a frequência de vibração de $16,67 \mathrm{~Hz}$.

Observações feitas por Silva et al. (2003) em duas passadas na colhedora mostram perdas médias de até $23,1 \%$ no volume de café no chão. No presente trabalho foram contabilizadas perdas médias na colheita de $4,5 \%$ e $1,5 \%$ para as faces leste e oeste, respectivamente, em uma única passada pela colhedora, demonstrando, portanto, observações iniciais promissoras em se tratando de colheita mecanizada, uma vez que a diferença nas perdas para as duas faces apontam para desenvolvimentos projetos que permitam regulagens diferenciadas para cada face de exposição das plantas. Entretanto, novos estudos necessitam ser realizados, sob diferentes condições de cultivo, para permitir respaldos conclusivos e recomendações sólidas.

Com relação à eficiência de colheita (Tabela 1), os valores encontrados foram superiores a 93\%, resultado este que pode ser considerado excelente para uma única passada da colhedora. Isso porque de acordo com Silva et al. (2000) a eficiência operacional de colheita pode chegar a $97 \%$, considerando-se todo o processo, geralmente realizado com duas passadas da colhedora.

$\mathrm{Na}$ avaliação realizada com as cartas de controle constatou-se para as variáveis danos às plantas e perdas na colheita que o processo permaneceu estável, pois não foram observados pontos fora dos limites superior e inferior de controle (Figuras $1 \mathrm{e}$ 2), tanto nas cartas de valores individuais como nas de amplitudes. Pode-se observar que as menores amplitudes dos danos e das perdas foram obtidas para a face de exposição leste, enquanto que os danos e as perdas encontrados na face oeste apresentaram maior variabilidade, retratada pela maior distância entre os limites superior e inferior de controle encontrado para estas faces. Ainda, pode-se observar em ambas as faces que os melhores resultados de danos, ou seja, a menor variabilidade e, consequentemente, a maior proximidade dos valores junto à média, foram encontrados para a velocidade $\mathrm{V}_{2}\left(0,45 \mathrm{~m} \mathrm{~s}^{-1}\right)$, uma vez que os pontos amostrados nesta velocidade, independente da face de exposição, situamse mais frequentemente ao redor da média.

As cartas de controle para a eficiência de colheita (Figura 3) apresentam vários pontos amostrados com erro tipo 1 , indicando que o processo se encontra fora de controle, uma vez que estes pontos situam-se acima ou abaixo dos limites de controle. Rezende et al. (2006) relatam que em 
lavoura irrigada os cafeeiros possuem seus frutos mais aderidos às plantas dificultando o processo de colheita, podendo isto ser uma possível explicação, visto que a irrigação retarda a maturação dos frutos (KARASAWA et al., 2002) deixando-os mais próximos ao estádio de maturação verde. Embora no momento de atuação pela colhedora nas parcelas experimentais a maturação dos frutos apresentasse $43 \%$ para o estádio verde, a eficiência média da colheita para as faces leste e oeste
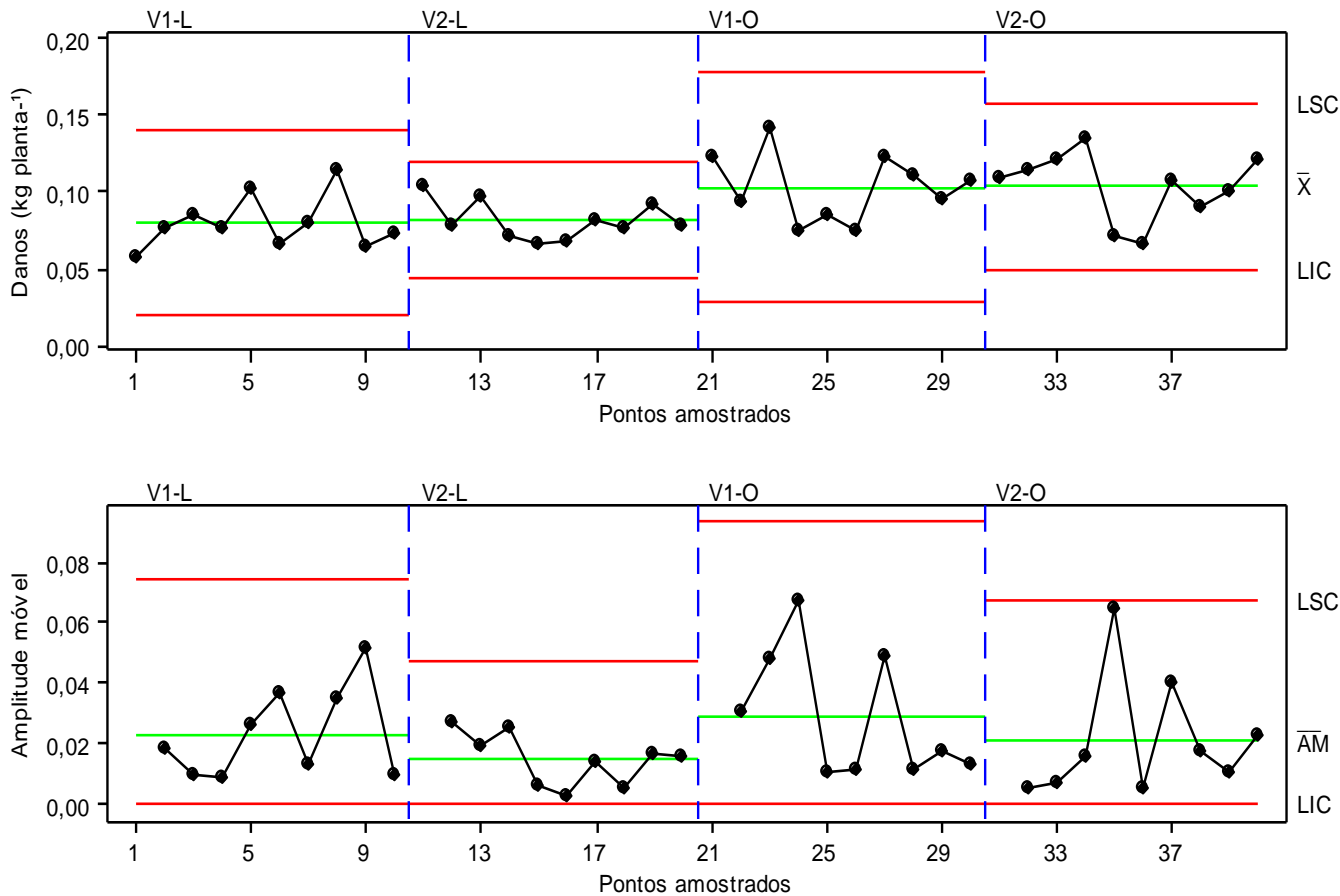

Figura 1. Cartas de controle nos pontos amostrados para as médias e amplitudes nas variáveis analisadas danos as plantas, perdas na derriça e eficiência de colheita dos cafeeiros Catuaí Amarelo IAC 62. UNESP, Jaboticabal, SP, 2012. alcançaram valores superiores a 93\% em uma única passada.

Pelos resultados obtidos na Tabela 1 , colhedora não afetaram os danos às plantas, perdas na colheita e a eficiência de colheita, possibilitando a escolha da maior velocidade de deslocamento no campo, de $0,45 \mathrm{~m} \mathrm{~s}^{-1}$, possibilitando o aumento da capacidade operacional em $32 \%$ as velocidades de deslocamento da 

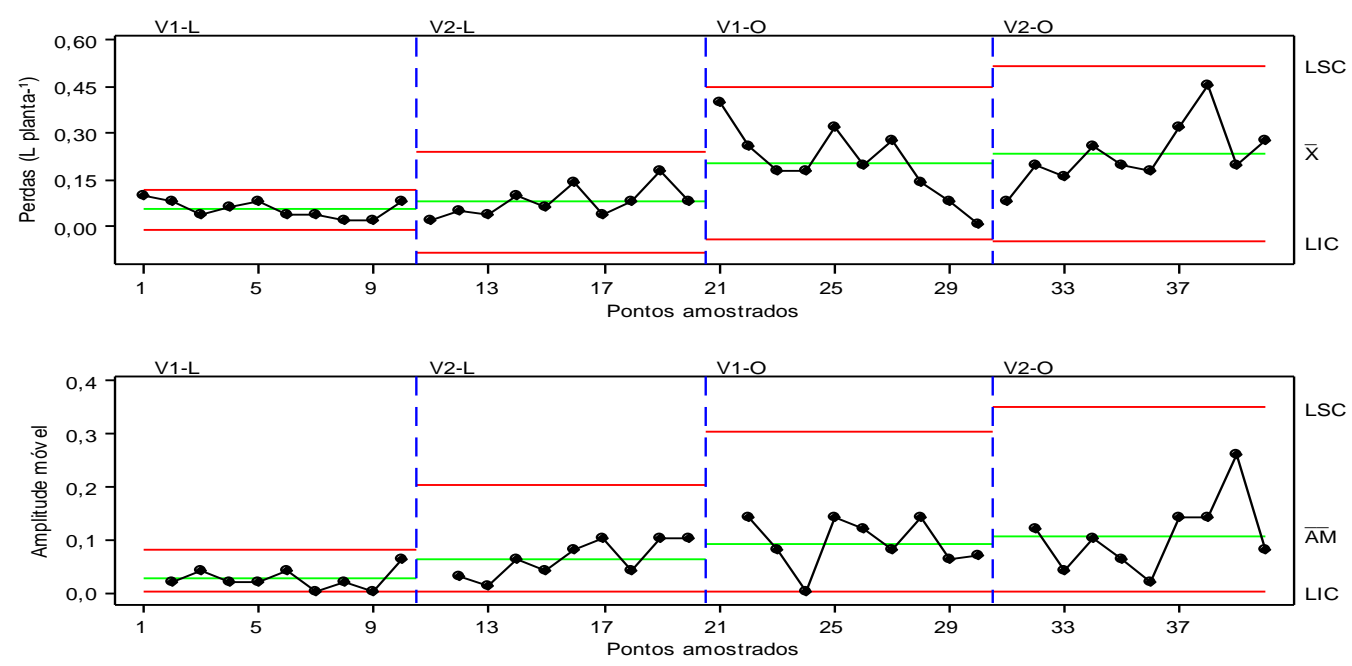

Figura 2. Cartas de controle nos pontos amostrados para as médias e amplitudes nas variáveis analisadas danos as plantas, perdas na derriça e eficiência de colheita dos cafeeiros Catuaí Amarelo IAC 62. UNESP, Jaboticabal, SP, 2012.
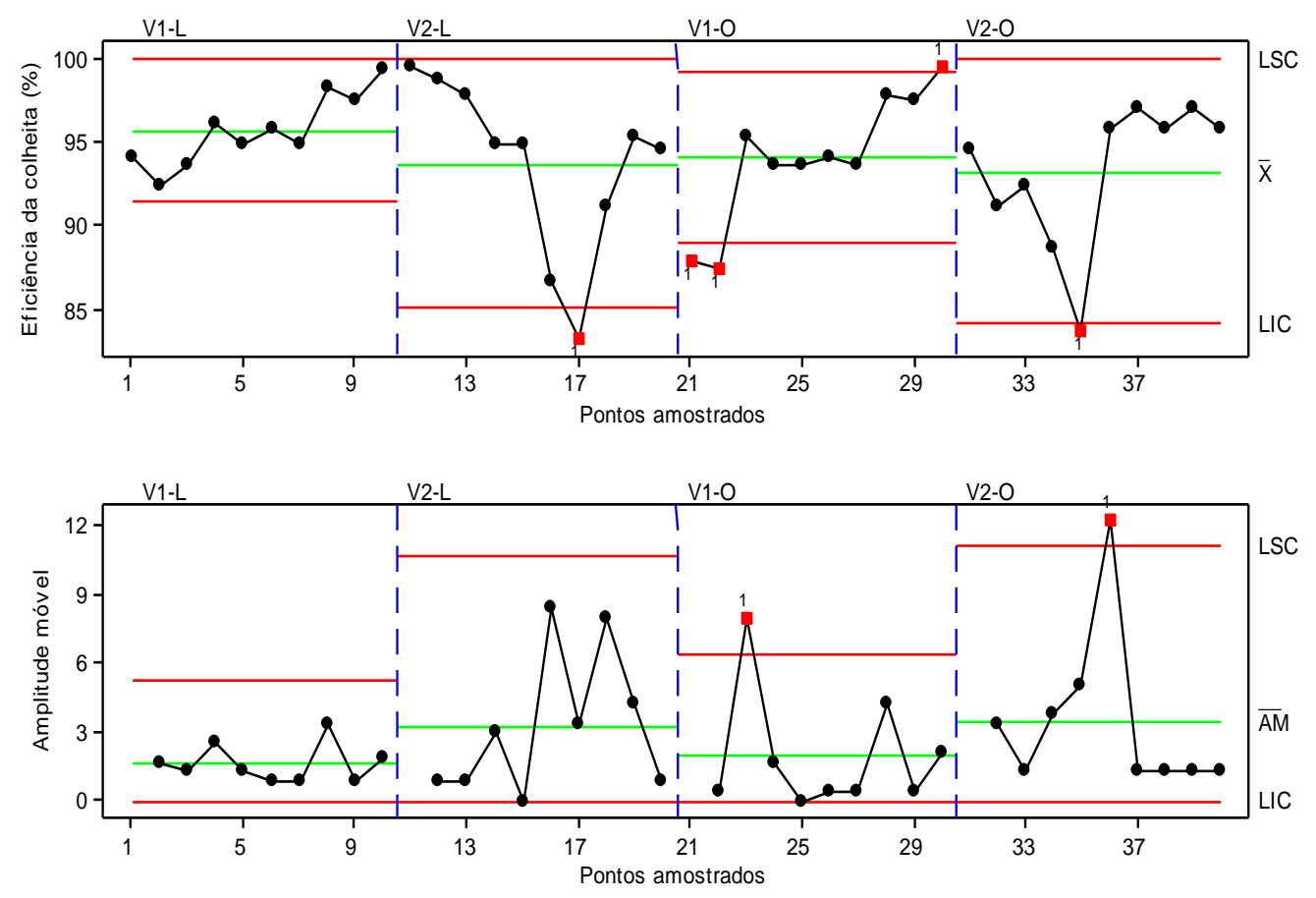

Figura 3. Cartas de controle nos pontos amostrados para as médias e amplitudes nas variáveis analisadas danos as plantas, perdas na derriça e eficiência de colheita dos cafeeiros Catuaí Amarelo IAC 62. UNESP, Jaboticabal, SP, 2012.

\section{CONCLUSÃO}

A velocidade de deslocamento estudada na colhedora não influenciou os danos às plantas, perdas e na eficiência de colheita. As faces de exposição influenciaram os danos aos cafeeiros e perdas na colheita mecanizada, sendo menor na face leste de exposição das plantas.

$\mathrm{O}$ processo foi considerado sob controle para as variáveis danos aos 
cafeeiros e perdas na colheita de café. A utilização de cartas de controle estatístico foi eficiente para avaliação da qualidade na colheita do café, sendo uma ferramenta alternativa em busca da melhoria no processo de colheita mecanizada da lavoura.

\section{AGRADECIMENTOS}

À empresa Cambuhy Agrícola Ltda., através do Eng $^{\circ}$ Agr $^{\circ}$ Gustavo Zanetti Pollo, por disponibilizar as avaliações de campo e pelo apoio na execução do trabalho.

Aos estudantes de graduação e pósgraduandos do Laboratório de Máquinas e Mecanização Agrícola (LAMMA) da UNESP Jaboticabal, pelo suporte prestado.

\section{REFERÊNCIAS BIBLIOGRÁFICAS}

ALVES, E. A.; PINTO, F. A. C.; QUEIROZ, D. M.; ZANDONADI, R. S.; SANTOS, N. T. Análise do efeito da face de exposição das plantas de café ao sol sobre a produção e maturação dos frutos. In: Congresso Brasileiro de Pesquisas Cafeeiras, 2004, São Lourenço. Resumos... Rio de Janeiro: Mapa/Procafé, 2004. p. 121-122.

EMBRAPA - Empresa Brasileira de Pesquisa Agropecuária Centro Nacional de Pesquisa de Solos. Sistema brasileiro de classificação de solos. Brasília: Embrapa Produção de Informação; Rio de Janeiro: Embrapa Solos, 2006. 412 p.

KARASAWA, S.; FARIA, M.A. de; GUIMARÃES, R.J. Resposta do cafeeiro cv. Topázio MG -1190 submetido a diferentes épocas de irrigação. Revista Brasileira de Engenharia Agrícola e Ambiental, Campina Grande, v. 6, n. 1, p. 28-34, 2002.
MATIELLO, J.B.; SILVA, W.J.; AGUIAR FILHO, E.C.; ARAÚJO, R.A.. Efeito da face de exposição do cafeeiro na produtividade e na qualidade dos frutos na região de Pirapora - MG. In: Congresso Brasileiro de Pesquisas Cafeeiras, 30, 2004; São Lourenço. Resumos... Rio de Janeiro: Mapa/Procafé, 2004. p. 01-02.

MATIELLO, J.B.; GARCIA， A.W.G.; ALMEIDA, S.R.; JAPIASSU, L.B. Melhorando a colheita do café, Boletim técnico, Varginha - MG, MAPA/PROCAFÉ, 2009, 56 p.

MINITAB. MINITAB 15 Statistical Software®: Minitab Inc., 2007.

OLIVEIRA, K.M.G. Desenvolvimento de um software para estimativa do azimute de linhas de plantio de cafeeiros. 2008. 66 p. Dissertação (Mestrado em Engenharia Agrícola) Universidade Federal de Lavras, Lavras, MG.

OLIVEIRA, E.; SILVA, F.M.; SALVADOR, N.; FIGUEIREDO, C.A.P. Influência da vibração das hastes e da velocidade de deslocamento da colhedora no processo de colheita mecanizada do café. Engenharia Agrícola, Jaboticabal, v. 27, n.3, p.714$721,2007$.

REZENDE, F.C.; OLIVEIRA, S. dos R.; FARIA, A, M.A. de; ARANTES, K.R. Características produtivas do cafeeiro (Coffea arabica L. cv. Topázio MG 1190), recepado e irrigado por gotejamento. Coffee Science, Lavras, v.1, n.2, p. 103-110, 2006.

SANTINATO, R.; FERNANDES, A.L.T.; FERNANDES, D.R. Irrigação na cultura do café. $2^{\mathrm{a}}$ Edição ampliada. Uberaba: O Lutador, 2008. 483 p. 
SANTOS, F.L.; QUEIROZ, D.M.; PINTO, F.A.C.; RESENDE, R.C. Efeito da frequência e amplitude de vibração sobre a derriça de frutos de café. Revista Brasileira de Engenharia Agrícola e Ambiental. v.14, n.4, p.425-431, 2010.

SILVA, C.A. da; TEODORO, R.E.F.; MELO, B. Produtividade e rendimento do cafeeiro submetido a lâminas de irrigação. Pesquisa Agropecuária Brasileira, Brasília, v. 43, n. 3, p. 387394, mar. 2008a.

SILVA, R.P da; CORRÊA, C.F.; CORTEZ, J.W.; FURLANI, C.E.A. Controle estatístico aplicado ao processo de colheita mecanizada de cana-de-açúcar. Engenharia Agrícola, Jaboticabal, v. 28, n.2, p. 292-304, abr./jun.2008b.

SILVA, F.C.; SILVA, F.M.; ALVES, M.C.; BARROS, M.M.; SALES, R.S. Comportamento da força de desprendimento dos frutos de cafeeiros ao longo do período de colheita. Ciência e Agrotecnologia, v.34, n.2, p. 468-474, 2010.

SILVA, F.M.; SALVADOR, N.; RODRIGUES, R.F.; TOURINO, E.S. Avaliação da colheita do café totalmente mecanizada. Engenharia Agrícola, Jaboticabal, v.23, n.2, p.309-315, maio/ago. 2003.

SILVA, F.M. da; RODRIGUES, R.F.; SALVADOR, N.; TOURINO, E.S.; SILVA, S.S.S. Custo da colheita mecanizada de café com colhedoras automotrizes no Sul de Minas. Engenharia na Agricultura, Viçosa, v.8, n.1, p.54-60, 2000. 